\title{
Effects of Textile Materials Harmful to Human Health
}

\author{
F. Akarslan ${ }^{a, *}$ And H. Demiralay ${ }^{b}$ \\ ${ }^{a}$ Süleyman Demirel University, Engineering Faculty, Departments of Textile Engineering, Isparta, Turkey \\ ${ }^{b}$ Isparta Directorate of Public Health, Central Community Health Center, Isparta, Turkey \\ Comprising the ecology of textile production, human ecology, as well as the waste ecology, the textile ecology \\ aims not to harm environment and people during all phases of the textile production, from fabric to garment \\ production. Several processes are applied to textiles, before the end product is obtained. We are intending to \\ take into consideration all phases of fabric and garment production, including the applied processes as well as the \\ used materials and chemicals. The remaining consumers also have a role in the pollution chain of textile industry. \\ Apparel products, purchased and used by consumers, contain chemicals harmful for the human health, and after \\ washing, the environmental impact of these products is inevitable. In this study, we investigate the effects of textile \\ materials harmful for the human health.
}

DOI: 10.12693/APhysPolA.128.B-407

PACS: 01.90.+g, 43.64.Gz

\section{Introduction}

Textile ecology aims not to harm environment and people in all phases of the textile production from fabric production to production of garments [1]. Fabric production and materials and chemicals, used for production of fabric, cause deterioration of ecological balance. Chemicals used in textile products may create a health hazard [1]. Textile industry is one of the most waterconsuming, chemicals-consuming and energy-consuming industries [2]. Dyeing of textiles requires high amounts of water (200 tons of water per ton of product) and some harmful chemical substances. Over 10000 types of dye are used for dyeing or printing on textiles [2-4].

On this background, the consumers also have a role in the textile products pollution chain. The apparel products, purchased and used by consumers often contain chemicals, harmful for the human health, and after washing the environmental impact of these products is inevitable [4]. Several processes are applied to textiles before the end product is obtained. We are intending to take into consideration all phases from fabric to garment production, taking into account the applied processes as well as the materials and chemicals used.

Harmful chemicals can be acquired through the skin, bronchially or through digestion [5-7]. Textile materials can cause allergic reactions [1, 8]. Textile materials can even be carcinogenic and mutagenic [9]. Textile products, which affect human and environmental health, should be taken into consideration. Chemical analysis of fabrics and production materials should be carried out, for production of healthy fabric, free from harmful substances.

\footnotetext{
* corresponding author; e-mail: afeyza@gmail.com
}

\section{Mutogenic and carcinogenic potential of textiles}

The mutogenicity of azo dyes [10, 11], and their potential to cause some types of cancer have been reported. Myslak et al. [12] have observed that painters had developed bladder cancer after long-time exposure to azo dyes. These compounds are mainly metabolized at the intestinal wall and in the liver, producing free aromatic amines that are potentially carcinogenic and mutagenic [13].

\section{Textile formaldehyde resins and allergic contact dermatitis}

Allergic contact dermatitis due to clothing is one of the most unfortunate dermatologic conditions. The affected individuals are often almost erythrodermic and experience a persistent intractable pruritus, which can be debilitating. Since 1926, formaldehyde-containing resins have been used in the clothing industry to make wrinkleresistant fabrics. These resins employ methylol reactive groups to crosslink cellulose fibers in cotton, linen, and rayon (cellulose-based natural polymer) garments. Formaldehyde-related contact allergy to clothing is still a concern today, despite efforts made in the textile industry in the US to switch to the resins imparting fabrics with lower amounts of free formaldehyde [14, 15]. The industry now claims that the average level of free formaldehyde, contained in the textiles made in the US, is approximately 100-200 ppm [15].

Allergic contact dermatitis due to formaldehyde present in textiles was commonly reported in the literature in the 1950s and 1960s. In recent years, the textile industry has attempted to lower the amount of free formaldehyde in wearing apparel and bedding fabrics, and the reports of contact allergy to textiles, caused by formaldehyde have become less common [16]. 


\section{Epoxy resins and allergic contact dermatitis}

Epoxy resins are commonly used at workplaces because of their physical strength, strong adhesive properties, ability to resist other chemicals, low shrinkage, and ease of curing. Epoxy resin is most commonly found in adhesives and glues for both, industrial and personal use. It may also be found in surface coatings such as paints and primers, electrical insulation, and in polyvinyl chloride products. It is thus important to recognize the role of occupational exposure to epoxy. Epoxy resins were implicated in a number of cases of allergic contact dermatitis and have subsequently become well-recognized irritant and sensitizing agents. Epoxy resin compounds can provoke sensitization after a single exposure in about $50 \%$ of people. Epoxy resins are well-known sensitizers and represent an occupational hazard for personnel who use or manufacture plastics, glues, paints, varnishes, composites and electrical equipment [17]. Most epoxy resins are based on the monomer diglycidyl ether of bisphenol A (DGEBA), which is also the most potent sensitizing molecule [18].

\section{Fiber additives and allergic contact dermatitis}

Fiber additives are chemicals incorporated into fibers to provide special properties, such as flame retardants, delusrtants, antioxidants, optical brighteners and ultraviolet light absorbers. The chemicals are added to the polymer solution or melt, so they become embedded and locked between the polymer fibers, as the solution coagulates or solidifies. One case of fiber additive dermatitis from 1985 was found in the literature to the present. The allergen was an ultraviolet light absorber, 2-(2-hydroxy-5-methylphenyl)benzotriazole, which had been added to spandex fibers. Arisu, et al. believe that another compound in the spandex was causing the sensitization [8].

\section{Metallic fibers and allergic contact dermatitis}

Metallic fibers are rarely used in fabrics, particularly the fabrics that are worn, because such fabric tends to be abrasive during wear [8].

\section{Wool fibers and prickle and itch}

The fabric containing fibers of larger diameter was evaluated as being rougher than the fabric with the smaller diameter fibers. The fabric containing the larger diameter fibers caused more subjects to itch and caused more intense itching than the fabric containing the smaller diameter fibers.

The audio technique was used to evaluated the finishes commonly used in the production of wool fabrics. Such data is being used to engineer wool fabric without prickle and itch $[8]$.

\section{Conclusions}

Fabric production, materials and chemicals used for production cause deterioration of ecological balance and human health. Making analysis of the chemicals and other substances in fabrics is very important and more research of this subject is necessary. Apparel products can contain harmful chemicals. We need to raise the awareness between the people, about the potentially harmful fabrics.

\section{References}

[1] K.L. Hatch, Text. Res. J. 54, 664 (1984).

[2] T. Bayraktar, Tekstil ve Konfeksiyon Sektöründe Ekoloji ve Ekolojik Etikler, İTKİB AR\&GE, Mevzuat Şubesi 2005.

[3] N. Kurtoğlu, D. Şenol, KSÜ Fen ve Mühendislik Dergisi, Tekstil ve Ekolojiye Genel Bakış 7, 26 (2004).

[4] Aromatic amines, in: Some aromatic amines, hydrazine and related substances, $N$-nitroso compounds and miscellaneous alkylating agents, International Agency for Research on Cancer (IARC), Monographs on the evaluation of the carcinogenic risk of chemicals to humans, vol. 4, 1998

[5] K. Golka, S. Kopps, Z.W. Myslak Toxicol. Lett. 151, 203 (2004).

[6] F. Rafi, J.E. Daugherty, Assessment of chemical exposures: Calculation methods for environmental professionals, CRC Press LLC 1997.

[7] Some Aromatic Amines, Organic Dyes, and Related Exposures, International Agency for Research on Cancer (IARC), Monographs on the evaluation of the carcinogenic risk of chemicals to humans, vol. 99, 2008.

[8] K.L. Hatch, H.I. Maibach, J. Am. Acad. Dermatol 32, 631 (1995); Contact Derm. 32, 319 (1995).

[9] A.R. Moll, Melliand Textilberichte 10, 836 (1991); Öko-Tex Standart 100.

[10] L. Busk, U.G. Ahlborg, Mutat. Res. 104, 225 (1982).

[11] J.F. Esancy, H.S. Freeman, L.D. Claxton Mutat. Res. 238, 1 (1990).

[12] Z.W. Myslak, H.M. Bolt, W. Brockmann, Am. J. Ind. Med. 19, 705 (1991).

[13] R. Gingell, J.W. Bridges, R.T. Willians, Xenobiotica I, 143 (1971).

[14] M.R. Stonecipher, E.F. Sheretz, Am. J. Contact Derm. 4, 172 (1993).

[15] J.F. Fowler, S.M. Skinner, D.V. Belsito, J. Am. Acad. Dermatol 27, 962 (1992).

[16] A.J. Scheman, P.A. Carroll, K.H. Brown, A.H. Osburn, Contact Dermatitis 38, 332 (1998).

[17] R.A. El-Azhary, J.A. Yiannias, J. Am. Acad. Derm. 47, 954 (2002).

[18] A. Ponte, M. Bruze, Contact Dermatitis 41, 235 (1999). 